\title{
Investigasi Kontaminasi Minyak Melalui Fingerprint Kimia di Estuari Muara Angke, Cimandiri dan Cilintang
}

\author{
Mohammad Agung Nugraha ${ }^{1 *}$ dan Tri Prartono² \\ 1*Program Studi Ilmu Kelautan Fakultas Pertanian, Perikanan, dan Biologi, Universitas Bangka \\ Belitung, Kampus Terpadu - UBB, Balunijuk, Kab.Bangka, Prov. Kepulauan Bangka Belitung, 33172 \\ 2Departemen IImu dan Teknologi Kelautan, Fakultas Perikanan dan Ilmu Kelautan, \\ Institut Pertanian Bogor \\ Jl. Lingkar Akademik, Gedung Marine Center, Bogor, 16680 \\ Email: mohammad.agung.n2361@gmail.com
}

\section{Abstract \\ Investigation of Oil Contamination through Chemical Fingerprint in Muara Angke Estuary, Cimandiri and Cilintang}

Polycyclic aromatic hydrocarbons (PAHs) and hopanes are one of the biomarker components that can be used in petroleum contamination tracing. The study was conducted with the objective of assessing petroleum contamination in sediment based on Polycyclic Aromatic Hydrocarbon (PAH) and Hopana components in Estuari Muara Angke, Cimandiri and Cilintang. Sediment samples were collected to a depth of $\pm 10 \mathrm{~cm}$. Sediment samples were dried by freezedryer then extracted and fractionated. The fractionated sample was analyzed by gas chromatography-mass spectrometry. Estuary Muara Angke and Cimandiri showed the presence of petroleum contamination while Cilintang was not detected.

Keywords : estuary, hopanes, PAH, petroleum, sediment

\begin{abstract}
Abstrak
Polisiklik aromatik hidrokarbon (PAH) dan hopana merupakan salah satu komponen biomarker yang dapat digunakan dalam penelusuran kontaminasi petroleum. Penelitian dilaksanakan dengan tujuan mengkaji kontaminasi petroleum dalam sedimen berdasarkan komponen Polisiklik Aromatik Hidrokarbon (PAH) dan Hopana di Estuari Muara Angke, Teluk Jakarta, Cimandiri-Teluk Pelabuhan Ratu dan Cilintang, Ujung Kulon. Contoh sedimen dikumpulkan hingga kedalaman $\pm 10 \mathrm{~cm}$. Contoh sedimen dikeringkan dengan alat freeze-dryer kemudian dilakukan ekstraksi dan fraksinasi. Sampel yang telah terfraksinasi dianalisis dengan alat kromatografi gas-spektrometri massa. Estuari Muara Angke dan Cimandiri menunjukkan adanya kontaminasi petroleum sedangkan Cilintang tidak terdeteksi.
\end{abstract}

Kata kunci : estuari, hopana, PAH, petroleum, sedimen

\section{PENDAHULUAN}

Biomarker (Biological marker) merupakan senyawa organik spesifik yang dapat digunakan dalam menduga serta menelusuri kontribusi kabon organik dari sumber yang berbeda menurut molekulnya (Parrish et al., 2000). Polisiklik aromatik hidrokarbon (PAH) dan Hopana merupakan komponen biomarker yang dapat digunakan dalam penelusuran sumber bahan organik. Komponen Lainnya yang dapat digunakan, seperti hidrokarbon alifatik (n-alkana), fatty acid, sterol, $n$-alkanol dan isoprenoid.

Polisiklik aromatik hidrokarbon (PAH) disebut juga sebagai polynuclear aromatic hydrocarbons (PNAs) merupakan kelompok 
senyawa organik yang bersifat hidrofobik dengan dua atau lebih gabungan ring aromatik, yang utamanya masuk ke lingkungan melalui proses antropogenik (Zhang et al., 2004; Boehm, 2006). PAH dapat terdeteksi pada kolom air, sedimen, biota akuatik serta makanan (Silva et al., 2007). PAH juga mempunyai efek mutagenik dan karsinogenik (Gomes and Azevedo, 2003).

Hopana merupakan pentasiklik triterpana yang umumnya terdiri dari 27 sampai dengan 35 atom karbon dengan komposisi struktur empat ring dengan enam atom karbon dan satu ring dengan lima atom karbon (Killops and Killops 1993; Wang et al., 2006). Kehadiran kontaminan petroleum pada sedimen dapat dilihat dari kehadiran biomarker hopana (Zaghdan et al., 2005).

Penelitian terkait PAH dan Hopana telah dilaksanakan secara luas baik itu pada perairan lakustrin, sungai dan laut (Gomes and Azevedo, 2003; Kassim, 2005; Gao and Chen, 2008; Wagener et al., 2010). Perairan Estuari Muara Angke-Teluk Jakarta merupakan bagian hilir dari salah satu anak Sungai Ciliwung. Perairan Estuari Muara Angke telah terindikasi tercemar. Hal tersebut dipengaruhi oleh tingginya aktivitas sekitar estuari dan lahan atas (daratan). Estuari Cimandiri yang yang berhulu dari kompleks Pegunungan Gede-Pangrango pada bagian timur laut dan Gunung Salak pada bagian utaranya merupakan perairan yang aktivitas sekitarnya mulai meningkat, seperti aktivitas dari nelayan, pelabuhan serta pembangunan Pembangkit Listrik Tenaga Uap (PLTU), tetapi tidak setinggi aktivitas di Teluk Jakarta. Estuari Cilintang yang masuk dalam kawasan Taman Nasional Ujung Kulon berperan penting dalam menjaga keseimbangan ekosistem dan kelestarian sumberdaya alam hayati. Ujung Kulon memiliki kekayaan sumberdaya hayati perairan seperti mangrove, padang lamun dan terumbu karang. Perbedaan lingkungan pada perairan Estuari Muara angke, Cimandiri dan Cilintang diduga memberikan perbedaan karakteristik PAH dan Hopana yang terdeposisi di dasar ketiga perairan. Kajian terkait biomarker pada perairan masih belum banyak dilakukan di Indonesia. Analisis biomarker dapat memberikan informasi yang penting dalam investigasi forensik lingkungan terkait indentifikasi karakteristik dan sumber biomarker (alami dan antropogenik) pada setiap lokasi. Penelitian dilaksanakan dengan tujuan mengkaji kontaminasi petroleum dalam sedimen berdasarkan komponen Polisiklik Aromatik Hidrokarbon (PAH) dan Hopana di Estuari Muara Angke, Teluk Jakarta, Cimandiri-Teluk Pelabuhan Ratu dan Cilintang, Ujung Kulon.

\section{MATERI DAN METODE}

\section{Lokasi Penelitian}

Penelitian dilaksanakan di Estuari Muara Angke-Teluk Jakarta yang berada pada 0605' 47.6" LS dan 106045'58.9"BT, CimandiriTeluk Pelabuhan Ratu yang berada pada 07000'32.5" LS dan 106032'11.5"BT dan Cilintang-Ujung Kulon yang berada pada 06048' 49.2" LS dan 105028'22.2"BT (Gambar 1).

\section{Pengambilan Sampel}

Pengumpulan contoh sedimen dilakukan pada 1 titik untuk masing-masing Estuari Muara Angke-Teluk Jakarta, CimandiriTeluk Pelabuhan Ratu dan Cilintang-Ujung Kulon. Titik pengambilan contoh sedimen dilihat posisinya (lintang dan bujur) dengan menggunakan alat Global Positioning System (GPS). Contoh sedimen permukaan $( \pm 10$ $\mathrm{cm}$ ) dikoleksi dengan menggunakan alat Van Veen grab (Mater et al., 2004). Contoh sedimen yang telah terkumpul pada grab dilakukan subcore, kemudian contoh sedimen dibungkus aluminium foil. Selanjutnya, disimpan dalam cold box. Di laboratorium contoh sedimen dibekukan dengan Freezer $\left(-20^{\circ} \mathrm{C}\right)$ untuk analisis lebih lanjut.

\section{Ekstraksi dan Fraksinasi}

Contoh sedimen dikeringkan dengan alat freeze-dryer (24 jam), kemudian dihomogenkan. Contoh sedimen yang telah dikeringkan kemudian ditimbang sebanyak $40 \mathrm{~g}$. Contoh diekstraksi dengan $120 \mathrm{~mL}$ pelarut campuran (1:1) diklorometana (DCM) dan methanol $(\mathrm{MeOH})$ dalam alat soxhlet $(24$ jam). Hasil dari ekstraksi divapkan dengan rotary evaporator hingga tersisa ekstrak 
kurang lebih $2 \mathrm{~mL}$. Ekstrak dihidrolisis dengan $6 \% \mathrm{KOH}$ dalam $\mathrm{MeOH}(30 \mathrm{~mL} ; 12$ jam) (Prartono and Wolff, 1998).

Fraksi netral didapat melalui ekstraksi dengan $n$-heksana $(3 \times 30 \mathrm{~mL})$. Fraksi cair divapkan $(\sim 0.5 \mathrm{~mL})$ dan dicampur dengan akuades yang sebelumnya telah diekstraksi dengan DCM $(25 \mathrm{~mL})$. Campuran diasamkan hingga $\mathrm{pH}$ menjadi $2(\mathrm{pH} 2)$ dengan $6 \mathrm{~N} \mathrm{HCl}$ dan fraksi asam didapat melalui ekstraksi dengan DCM $(3 \times 30 \mathrm{~mL})$. Selanjutnya, divapkan (tanpa nitrogen) hingga diperoleh $\pm 2 \mathrm{~mL}$ dan dimasukkan dalam gelas vial, kemudian divapkan dengan nitrogen hingga kering. Pelarut $n$-heksana ditambahkan 0.5 $\mathrm{mL}$ kedalam gelas vial bila akan dianalisis dengan GC-MS (Prartono and Wolff, 1998).

Fraksinasi dimulai dengan memasukkan fraksi netral ke kolom kromatografi yang telah terisi silika gel (5\% dideaktivasi silika; $10 \mathrm{~g}$ ). Berikut fraksi yang diperoleh : (I) fraksi alifatik diperoleh dengan mengelut kolom dengan $30 \mathrm{~mL} n$-heksana, (II) fraksi aromatik diperoleh dengan mengelut campuran $30 \mathrm{~mL}$ dari $\mathrm{n}$ heksana : diklorometana (90:10) diikuti oleh $20 \mathrm{~mL}$ campuran $50 \%$ diklorometana dalam n-heksana (50:50). Selanjutnya, hasil tiap fraksi divapkan (tanpa nitrogen) hingga diperoleh $\pm 2 \mathrm{~mL}$ dan dimasukkan dalam gelas vial.
Sampel yang telah dimasukkan dalam gelas vial kemudian diuapkan dengan nitrogen hingga kering. Pelarut $n$-heksana ditambahkan $0.5 \mathrm{~mL}$ kedalam gelas vial bila akan dianalisis dengan GC-MS (Prartono and Wolff, 1998).

\section{Analisis Kromatografi Gas Spketrofotometri Massa}

Analisis kromatografi gas-spektro-metri massa (gas chromatography-mass spectrometry/ GC-MS) menggunakan kromatografi gas Shimadzu QP2010 yang dilengkapi dengan kolom silika DB-5 ms (panjang $30 \mathrm{~m} ; 0.32 \mathrm{~mm}$ diameter dalam dan $0.25 \mu \mathrm{m}$ ketebalan lapis film, serta helium sebagai gas pendorong. Kroma-tografi gas menggunakan mode injeksi split dengan rasio 10:1. Suhu oven kromatografi gas diprogram dari 40 sampai $300{ }^{\circ} \mathrm{C}$ pada laju $6{ }^{\circ} \mathrm{C} /$ menit setelah satu menit dan dibiarkan konstan pada $300^{\circ} \mathrm{C}$ selama 20 menit. Kondisi GC-MS adalah ionisasi potensial/ electron energy $70 \mathrm{eV}$, ion source temperature $230^{\circ} \mathrm{C}$ dan interface temperature $250^{\circ} \mathrm{C}$. Full mass data dicatat antara 45-600 Dalton setiap detik. Data dicatat dan diproses/ analisis dengan perangkat lunak GCMS Real Time Analysis dan GCMS Postrun Analysis.

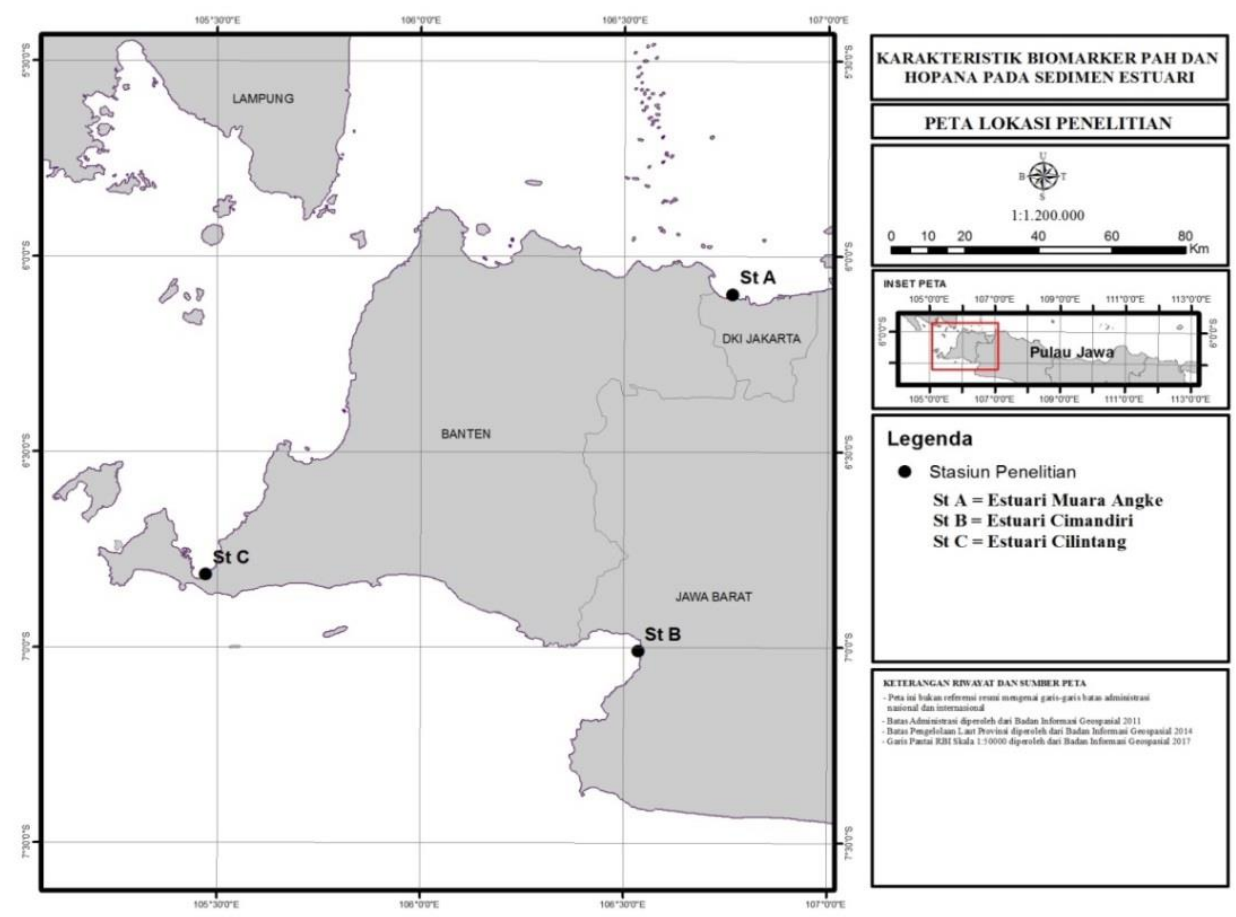

Gambar 1. Peta lokasi penelitian 


\section{HASIL DAN PEMBAHASAN}

\section{Polisiklik Aromatik Hidrokarbon (PAH)}

Karakteristik PAH yang terdeteksi pada sedimen permukaan Estuari Muara angke, Teluk Jakarta yaitu naphtalene, metilnapthalene, dimetilnaphtalene, trimetilnapthalene, fluorene, 2,6-diisopropilnaphtalene, phenantrene dan metilphenantrene. Selanjutnya, sedimen permukaan Estuari Cimandiri, Teluk Pelabuhan Ratu dicirikan dengan kehadiran naphtalene, metilnapthalene, dimetilnaphtalene, trimetilnapthalene, 2,6-diisopropilnaphtalene, phenantrene dan metilphenantrene (Gambar 2 dan 3). Pada sedimen permukaan Estuari Cilintang, Ujung Kulon biomarker PAH tidak terdeteksi.

PAH yang terdeteksi pada Estuari Muara Angke dan Cimandiri dikarakterisasi dengan jumlah ring benzene 2 dan 3 . Hal ini menunjukkan bahwa pada sedimen Estuari Muara Angke dan Cimandiri utamanya telah terkontaminasi oleh petroleum (Zhang et al., 2004; Boehm, 2006; Bouloubassi et al., 2006). Konsentrasi PAH yang diperoleh pada sedimen permukaan Estuari Muara Angke berkisar antara 1.36-26.15 ng/g berat kering sedimen dengan konsentrasi total PAH yaitu $104.33 \mathrm{ng} / \mathrm{g}$ berat kering sedimen. Selanjutnya, konsentrasi PAH pada sedimen permukaan Estuari Cimandiri berkisar antara 4.51-71.56 $\mathrm{ng} / \mathrm{g}$ berat kering sedimen dengan total PAH $185.23 \mathrm{ng} / \mathrm{g}$ berat kering sedimen.

Karakteristik PAH yang terdeteksi pada sedimen Estuari Muara Angke dan Cimandiri terdiri atas PAH bercabang atau alkil dan tidak bercabang atau non-alkil. Karakteristik PAH (Polisiklik Aromatik Hidrokarbon) yang terdeteksi pada sedimen Estuari Muara Angke dan Cimandiri didominasi oleh PAH

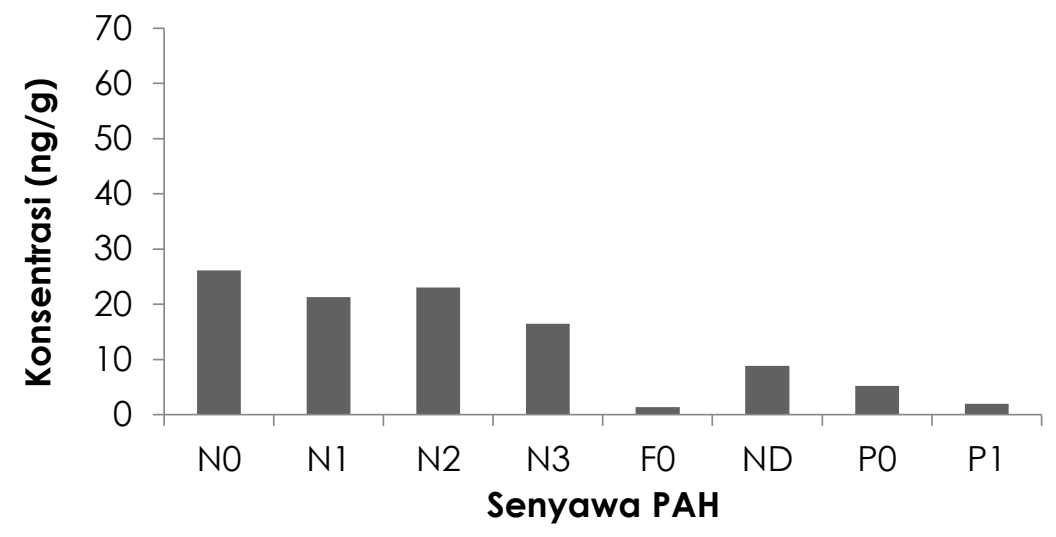

Gambar 2. Karakteristik sebaran PAH pada sedimen Estuari Muara Angke (NO = Naphtalene; $\mathrm{Nl}=$ C1-Napthalene; N2 = C2-Naphtalene; N3 = C3-Naphthalene; FO = Fluorene; ND = 2,6Diisopropilnaphtalene; $\mathrm{PO}=$ Phenantrene; $\mathrm{P} 1=\mathrm{C} 1$-Phenantrene).

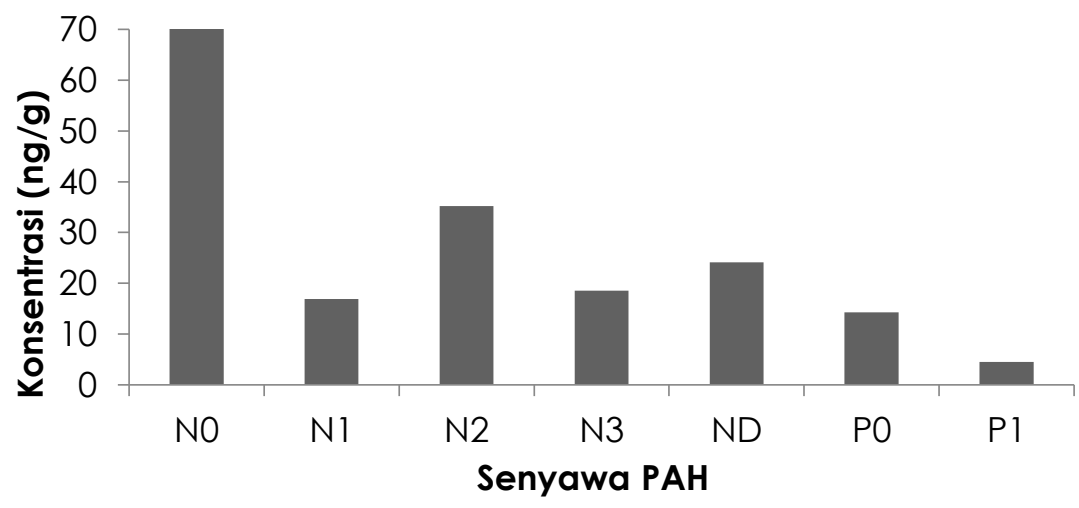

Gambar 3. Karakteristik sebaran PAH pada sedimen Estuari Cimandiri (NO = Naphtalene; $\mathrm{N1}=\mathrm{C} 1$ Napthalene; $\mathrm{N2}=\mathrm{C} 2$-Naphtalene; $\mathrm{N3}=\mathrm{C} 3$-Naphthalene; $\mathrm{ND}=2,6$ Diisopropilnaphtalene; $\mathrm{PO}=$ Phenantrene; $\mathrm{P} 1=\mathrm{C} 1$-Phenantrene) . 
bercabang (alkil) yaitu metilnaphthalene, dimetilnaphthalene, trimetilnapthalene, 2,6diisopropilnaphtalene dan metilphenantrene. Relatif melimpahnya PAH alkil atau bercabang daripada PAH induk atau tidak bercabang pada sedimen Estuari Muara Angke dan Cimandiri merupakan ciri dari dominannya PAH yang berasal petroleum atau petrogenik (Neff, 1979; Medeiros et al., 2005; Boehm, 2006).

Komponen naphthalene yang terdeteksi pada Estuari Muara Angke dan Cimandiri berasal dari sumber petrogenik (Boehm, 2006). Selanjutnya, komponen fluorene yang terdeteksi pada Estuari Muara Angke juga berasal dari sumber petrogenik (Shimoyama et al., 2000; Boehm, 2006).

PAH yang terdeteksi pada Estuari Muara Angke dan Cimandiri juga dikarakterisasi oleh kemunculan PAH tidak bercabang yaitu phenantrene yang dapat berasal dari sumber petrogenik dan pyrogenik (Gogou et al., 1998; Boehm, 2006). Estuari Muara Angke dan Cimandiri mempunyai nilai rasio $\sum$ metilphenantrene terhadap phenanthrene yang diperoleh $<1$ yaitu 0.38 dan 0,32 menunjukkan dominannya senyawa induk phenanthrene. Hal tersebut dapat diduga sumber phenanthrene pada sedimen Estuari Muara Angke dan Cimandiri utamanya berasal dari pyrogenik atau hasil pembakaran bahan bakar fosil, sedangkan nilai rasio >1 menunjukkan dominannya kontribusi dari petrogenik (Gogou et al., 1998; Kavouras et al., 1999). Komponen PAH yang terdeteksi pada Estuari Muara Angke dan Cimandiri secara keseluruhan berasal dari sumber petrogenik dan pyrogenik, dimana sumber $\mathrm{PAH}$ yang utama berasal dari petrogenik.

\section{Hopana}

Hopana yang ditemukan pada sedimen Estuari Muara Angke, Teluk Jakarta berkisar antara $\mathrm{C}_{27}$ sampai $\mathrm{C}_{35}$ dengan kode senyawa Ts, Tm, H29, C29Ts, H30, M30, H31S, $\mathrm{H} 31 \mathrm{R}, \mathrm{H} 32 \mathrm{~S}, \mathrm{H} 32 \mathrm{R}, \mathrm{H} 33 \mathrm{~S}, \mathrm{H} 33 \mathrm{R}, \mathrm{H} 34 \mathrm{~S}, \mathrm{H} 34 \mathrm{R}$, H35S dan H35R dan Cimandiri berkisar antara $\mathrm{C}_{27}$ sampai $\mathrm{C}_{31}$ dengan kode senyawa Ts, Tm, H29, C29Ts, H30, M30, H31S dan H3IR (Tabel 1). Kehadiran hopana pada penelitian ini semakin menguatkan adanya indikasi kontaminasi petroleum yang sebelumnya ditunjukkan oleh kehadiran PAH. Pada sedimen permukaan Estuari Cilintang, Ujung Kulon biomarker Hopana tidak terdeteksi.

Komponen hopana dengan kelimpahan tertinggi pada sedimen Estuari Muara Angke yaitu 17a(H),21ß(H)-hopana $\left(\mathrm{C}_{30} \mathrm{H}_{52}\right)$ (Gambar 4). Tingginya komponen tersebut ditemukan juga pada sedimen permukaan Estuari Sungai Pearl, Laut Cina Selatan (Gao et al., 2007). yaitu Ts : $18 \mathrm{a}(\mathrm{H}), 21 \beta(\mathrm{H})-22,29,30$-trisnorhopane $\quad\left(\mathrm{C}_{27} \mathrm{H}_{46}\right)$ (Gambar 5).

Tabel 1. Komponen hopana pada lokasi penelitian

\begin{tabular}{|c|c|}
\hline Kode & Senyawa \\
\hline Ts & $18 \mathrm{a}(\mathrm{H}), 21 \beta(\mathrm{H})-22,29,30$-trisnorhopane $\left(\mathrm{C}_{27} \mathrm{H}_{46}\right)$ \\
\hline $\mathrm{Tm}$ & $17 a(H), 21 \beta(H)-22,29,30$-trisnorhopane $\left(\mathrm{C}_{27} \mathrm{H}_{46}\right)$ \\
\hline H29 & 17a $(\mathrm{H}), 21 \beta(\mathrm{H})-30$-norhopane $\left(\mathrm{C}_{29} \mathrm{H}_{50}\right)$ \\
\hline C29Ts & $18 a(H), 21 \beta(H)-30$-norneohopane $\left(\mathrm{C}_{29} \mathrm{H}_{50}\right)$ \\
\hline H3O & $17 a(H), 21 \beta(H)$-hopane $\left(\mathrm{C}_{30} \mathrm{H}_{52}\right)$ \\
\hline M30 & $17 \beta(\mathrm{H}), 21 \mathrm{a}(\mathrm{H})$-hopane / moretane $\left(\mathrm{C}_{30} \mathrm{H}_{52}\right)$ \\
\hline H31S & 22S-17a(H),21ß(H)-homohopane $\left(\mathrm{C}_{31} \mathrm{H}_{54}\right)$ \\
\hline $\mathrm{H} 31 \mathrm{R}$ & 22R-17a(H),21ß(H)-homohopane $\left(\mathrm{C}_{31} \mathrm{H}_{54}\right)$ \\
\hline $\mathrm{H} 32 \mathrm{~S}$ & $22 \mathrm{~S}-17 \mathrm{a}(\mathrm{H}), 21 \beta(\mathrm{H})$-bishomohopane $\left(\mathrm{C}_{32} \mathrm{H}_{56}\right)$ \\
\hline $\mathrm{H} 32 \mathrm{R}$ & 22R-17a(H),21ß(H)-bishomohopane $\left(\mathrm{C}_{32} \mathrm{H}_{56}\right)$ \\
\hline H33S & 22S-17a(H),21ß(H)-trishomohopane $\left(\mathrm{C}_{33} \mathrm{H}_{58}\right)$ \\
\hline H33R & 22R-17a(H),21 $\beta(\mathrm{H})$-trishomohopane $\left(\mathrm{C}_{33} \mathrm{H}_{58}\right)$ \\
\hline $\mathrm{H} 34 \mathrm{~S}$ & $22 \mathrm{~S}-17 \mathrm{a}(\mathrm{H}), 21 \beta(\mathrm{H})$-tetrakishomohopane $\left(\mathrm{C}_{34} \mathrm{H}_{60}\right)$ \\
\hline H34R & $22 \mathrm{R}-17 \mathrm{a}(\mathrm{H}), 21 \beta(\mathrm{H})$-tetrakishomohopane $\left(\mathrm{C}_{34} \mathrm{H}_{60}\right)$ \\
\hline H35S & $22 \mathrm{~S}-17 \mathrm{a}(\mathrm{H}), 21 \beta(\mathrm{H})$-pentakishomohopane $\left(\mathrm{C}_{35} \mathrm{H}_{62}\right)$ \\
\hline $\mathrm{H} 35 \mathrm{R}$ & $22 \mathrm{R}-17 \mathrm{a}(\mathrm{H}), 21 \beta(\mathrm{H})$-pentakishomohopane $\left(\mathrm{C}_{35} \mathrm{H}_{62}\right)$ \\
\hline
\end{tabular}




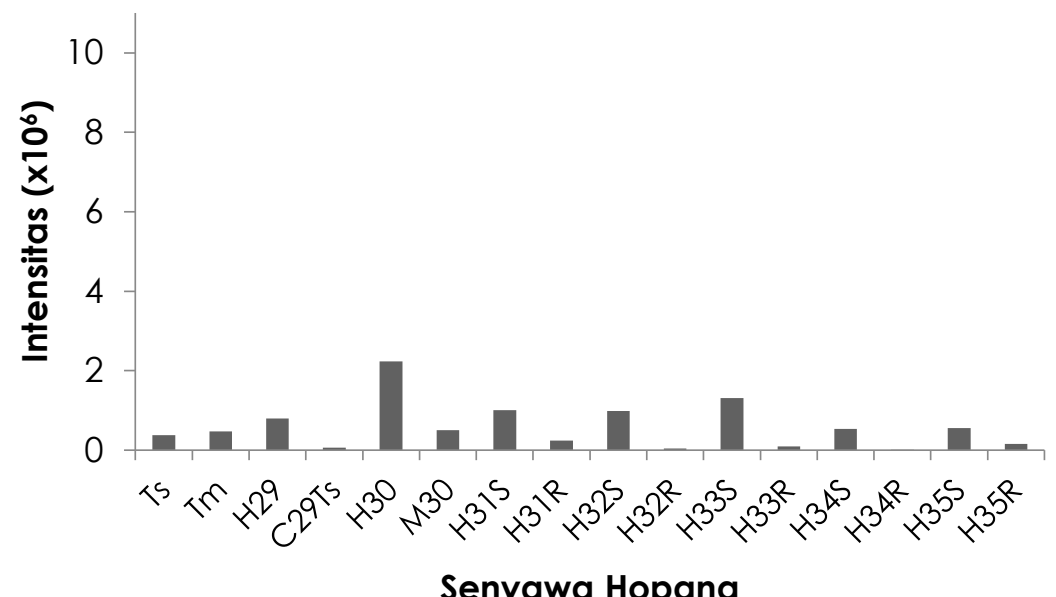

Gambar 4. Karakteristik sebaran hopana pada sedimen Estuari Muara Angke.

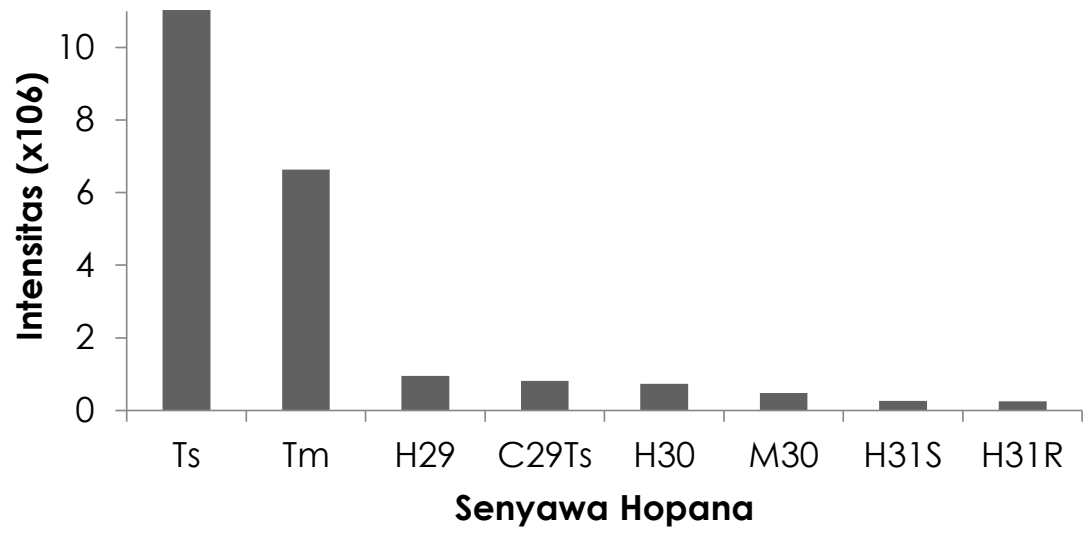

Gambar 5. Karakteristik sebaran hopana pada sedimen Estuari Cimandiri.

Hopana yang ditemukan pada sedimen Estuari Muara Angke dan Cimandiri didominasi konfigurasi $17 \mathrm{a}(\mathrm{H}), 21 \beta(\mathrm{H})$ atau $a \beta$ yang merupakan karakteristik petroleum karena besarnya kestabilan thermodinamika dibandingkan seri epimer yang lain $(\beta \beta$ dan ßa) (Peters and Moldowan, 1993). Konfigurasi a $\beta$ yang merupakan karakteristik petroleum ditemukan juga pada lapisan permukaan sedimen pantai Sfax, Laut Mediterania dan Estuari Sungai Pearl, Laut Cina Selatan (Zaghdan et al., 2005; Gao et al., 2007).

\section{KESIMPULAN}

PAH pada Estuari Muara Angke dan Cimandiri menunjukkan adanya masukan dari sumber petrogenik dan pyrogenik, dimana sumber PAH utamanya berasal dari petrogenik. Kehadiran hopana pada Estuari
Muara Angke dan Cimandiri semakin menguatkan adanya indikasi kontaminasi petroleum atau petrogenik. Pada Estuari Cilintang tidak terdeteksi adanya komponen biomarker PAH dan Hopana. Perbedaan kontribusi masukan organik tersebut karena pada Estuari Muara Angke dan Cimandiri masukan bahan organik dipengaruhi oleh aktivitas dari daratan sekitar estuari, seperti lalu lintas kapal tanker pembawa minyak, domestik, industri, pelabuhan dan nelayan. Sedangkan pada Estuari Cilintang jauh dari aktivitas manusia.

\section{DAFTAR PUSTAKA}

Boehm, P.D., 2006. Polycyclic aromatic hydrocarbons (PAHs), Morrison, R.D. and Murphy, B.L. (ed.), Environmental Forensics, Academic Press, London. 
Bouloubassi, I., Mejanelle, L., Pete, R., Fillaux, J., Lorre, A., \& Point, V. 2006. PAH Transport by Sinking Particles in The Open Mediterranean Sea: A 1 Year Sediment Trap Study. Mar. Poll. Bull., 52:560-571. DOI: 10.1016/j.marpolbul.2005.10.003

Gao, X., Chen, S., Xie, X., Long, A. \& Ma, F. 2007. Non-aromatic hydro-carbons in surface sediment near the pearl river estuary in the South China Sea. Environ. Poll. 148(1):40-47.

Gao, X. \& Chen, S. 2008. Petroleum pollution in surface sediment of day Bay, South China, revealed by chemical finger printing of ali-phatic and alicyclic hydrocarbons. Estuarine, Coast. Shelf Sci. 80(1):95-102.

Gogou, A.I., Apostolaki, M., \& Stephanou, E.G. 1998. Determination of organic molecular markers in marine aerosols and sediments: one-step flash chromatography compound class fractionation and capillary gas chromatographic analysis. J. Chromatograp. A. 799(1-2):215-231.

Gomes, A.D.O. \& Azevedo, D.D.A., 2003. Aliphatic and aromatic hydrocarbons in tropical recent sediments of Campos dos Goytacazes, RJ, Brazil. J. Braz. Chem. Soc. 14(3):358-368. DOI : 10.1590/S010350532003000300004

Kassim, T.A. 2005. Forensic Analysis and source partitioning of aliphatic hydrocarbon contamination in Lake Maruit aquatic sediments. Egyptian J. Aqua. Res. 31 (2):166-182.

Kavouras, I.G., Lawrence, J., Koutrakis, P., Stephanou, E.G., \& Oyola, P. 1999. Measurment of Particulate Aliphatic and Polynuclear Aromatic Hydrocarbons in Santiago de Chile:Source Reconciliation and Evaluation of Sampling Artifacts. Atmosph. Environ. 33:4977-4986.

Killops, S.D. \& Killops, V.J. 1993. An Introduction to organic geochemistry, Longman Group UK Ltd, London.

Mater, L., Alexandre, M.R., Hansel, F.A. \& Madureira, L.A.S. 2004. Assessment of lipid compounds and phosphorus in mangrove sediment of Santa Catarina Island, SC, Brazil. J. Braz. Chem. Soc. 15(5):725-734. DOI : 10.1590/S0103-50532 004000500019
Medeiros, P. M., Bícego, M. C., Castelao, R. M., Del Rosso, C., Fillmann, G., \& Zamboni, A. J. 2005. Natural and anthropogenic hydrocarbon inputs to sediments of Patos Lagoon Estuary, Brazil. Environ. Int. 31 (1):77-87.

Neff, J.M. 1979. Polycyclic Aromatic Hydrocarbon in The Aquatic Environment : Sources, Fates and Biological Effects, Applied Science, Publishers Ltd, London.

Parrish, C. C., Abrajano, T. A., Budge, S. M., Helleur, R. J., Hudson, E. D., Pulchan, K., \& Ramos, C. 2000. Lipid and phenolic biomarkers in marine ecosystems: analysis and applications. In Marine chemistry. pp. 193-223. Springer, Berlin, Heidelberg.

Peters, K.E. \& Moldowan, J.M. 1993. The Biomarker Guide: Interpreting Molecular Fossils in Petroleum and Ancient Sediments,Prentice-Hall, Inc. Englewood Cliffs, New Jersey.

Prartono, T. \& Wolff, G.A. 1998. Organic geochemistry of lacustrine sediment: a record of the changing trophic status of Rostherne Mere, U.K. Organic Geochem. 28(1 1):729-747.

Shimoyama, A., Hagiwara, M., \& Nomoto $S$. 2000. Naphthalenes in Neogene Sediments of The Shinjo Basin, Japan. Geochem. J., 34:333-340.

Silva, L.S.V.da., Azevedo, D.D.A., \& Neto, F.R.D.A. 2007. Distribution of polycyclic aromatic hydrocarbons in surface sediments and waters from Guanabara Bay, Rio de Janeiro, Brazil. J. Braz. Chem. Soc., 18(3):628-637.

Wang, Z., M. Fingas, C. Yang, \& J.H. Christensen. 2006. Crude oil and refined product finger printing: principles, Morrison, R.D., Murphy, B.L., editor. Environmental Forensics, Academic Press, London.

Wagener, A., Hamacher, C., Farias, C., Godoy, J. M., \& Scofield, A. 2010. Evaluation of tools to identify hydrocarbon sources in recent and historical sediments of a tropical bay. Marine Chemistry, 121(1-4):67-79. DOI : 10.1016/j.marchem.2010.03.005

Zhang, J., Cai, L., Yuan, D. \& Chen, M. 2004. Distribution and sources of polynuclear aromatic hydrocarbons in mangrove surficial sediments of Deep Bay, China. 
Mar. Poll. Bull., 49(5-6):479-486. DOI: 10.1016/j.marpolbul.2004.02.030

Zaghdan, H., Kallel, M., Louati, A., Elleuch, B., Oudot, J. and Saliot, A. 2005. Hydrocarbon in surface sediment from the Sfax Coastal Zone, (Tunisia) Mediterranean Sea. Mar. Poll. Bull. 50(11):1287-1294. DOI : 10.1016/j.marpol bul.2005.04.045 